\title{
Can fully automated detection of corticospinal tract damage be used in stroke patients? OPEN
}

Nancy Kou, MSc Chang-hyun Park, PhD Mohamed L. Seghier, $\mathrm{PhD}$

Alexander P. Leff, PhD Nick S. Ward, MD

Correspondence to Ms. Kou: n.kou.11@ucl.ac.uk
Supplemental data at www.neurology.org

\section{ABSTRACT}

Objective: We compared manual infarct definition, which is time-consuming and open to bias, with an automated abnormal tissue detection method in measuring corticospinal tract-infarct overlap volumes in chronic stroke patients to help predict motor outcome.

Methods: Using diffusion tensor imaging and probabilistic tractography, 4 corticospinal tracts from the primary motor cortex, dorsal and ventral premotor cortices, and supplementary motor area to the ipsilateral lower pons were reconstructed in 23 healthy controls. Tract-infarct overlap volume of each of the 4 corticospinal tracts was determined by overlapping the patients' lesions onto the control tract templates, using both manually and automatically defined infarcts in 51 patients. Correlations with upper limb motor impairment were assessed and both methods were directly compared using intraclass correlations (ICC).

Results: Greater impairment was seen in patients with greater corticospinal tract-infarct overlap with either method $\left(r_{\text {manual }}\right.$ range $=0.32-0.46 ; r_{\text {automated }}$ range $\left.=0.42-0.57\right)$. Consistency between manual and automated methods was good to excellent for all 4 corticospinal tracts (ICC range $=0.71-0.80$ ).

Conclusions: Our results demonstrate that automated infarct identification performs equally as well as a manual method in quantifying corticospinal tract-infarct overlap following stroke.

Neurology ${ }^{\circledR} 2013 ; 80: 2242-2245$

\section{GLOSSARY}

ARAT = Action Research Arm Test; ICC = intraclass correlation coefficient; $\mathbf{M} \mathbf{1}=$ primary motor cortex; $\mathbf{N H P T}=$ Nine-Hole Peg Test; PMd = dorsal premotor cortex; PMv = ventral premotor cortex; SMA = supplementary motor area

The extent of corticospinal tract damage after stroke correlates with motor impairment and can be calculated by measuring the overlap between the patient's infarct and control subjects' reconstructed corticospinal tracts. ${ }^{1,2}$ Corticospinal tract volume and integrity can be reliably determined using diffusion tensor imaging tractography, ${ }^{3}$ but the current practice of defining infarcted tissue manually ${ }^{1,2}$ is time-consuming and open to bias. ${ }^{4}$ Automated methods of infarct identification address this problem and increase the translational potential of corticospinal tract injury quantification to clinical practice. The aim of this study therefore was to confirm the relationship between motor impairment, in particular of the upper limbs, and corticospinal tract-infarct overlap in a cohort of chronic stroke patients, and to compare this approach using manual and automated methods for defining infarcted tissue.

METHODS We recruited chronic stroke patients at least 3 months after first-ever stroke and with weakness of wrist and finger extensors for at least 48 hours after the onset of symptoms. Age-matched healthy volunteers with no history of neurologic disease participated. Subjects with standard MRI exclusion criteria were not studied.

Patients' upper limb motor performance was assessed with the Action Research Arm Test (ARAT), Nine-Hole Peg Test (NHPT), Motricity Index, and grip strength. The first principal component of these 4 scores was taken as a representative measure of motor impairment.

We used probabilistic tractography ${ }^{5}$ implemented in FSL (http://www.fmrib.ox.ac.uk/fsl/) to reconstruct descending pathways in control participants from the 4 main cortical motor areas that contribute to the corticospinal tract: primary motor cortex (M1), dorsal

From the Sobell Department of Motor Neuroscience (N.K., C.H.P., N.S.W.) and Wellcome Trust Centre for Neuroimaging (M.L.S.), UCL Institute of Neurology; Institute of Cognitive Neuroscience (N.K., A.P.L.); and The National Hospital for Neurology and Neurosurgery (A.P.L., N.S.W.), London, UK.

Go to Neurology.org for full disclosures. Funding information and disclosures deemed relevant by the authors, if any, are provided at the end of the article. This is an open access article distributed under the Creative Commons Attribution License, which permits unrestricted use, distribution, and reproduction in any medium, provided the original work is properly cited. 
and ventral premotor cortices (PMd and PMv), and supplementary motor area (SMA) to the ipsilateral lower pons via the posterior limb of the internal capsule and upper pons. The output tracts for each control subject, mapped into a standard Montreal Neurological Institute space, were superimposed and binarized so that a value of 1 indicates the presence of a tract in more than half of our healthy subjects and a value of 0 indicates the lack of a tract (figure 1).

Patients' infarcts were identified from normalized T1-weighted structural images using 2 methods. First, infarcts were defined by visual inspection (N.K. and N.W.) whereby voxels within the infarct were given a value of 1 and those outside a value of 0 . Secondly, the automated lesion identification toolbox ${ }^{6}$ was used to estimate weighted lesions by comparing each voxel within the patient's gray or white matter to that in the same location in every control subject to yield a degree of abnormality (ranging from 0 to 1). Tract-infarct overlap was calculated by multiplying the infarct value by the control corticospinal tract template value in each voxel (figure 1).

For each of the 4 corticospinal tracts, Pearson correlation coefficients were determined between motor impairment and values for each infarct identification method separately (SPSS 20.0, IBM, New York, NY), and compared using Fisher $r-z$ transformations (figure 2). Covariates considered were age and time since stroke. Statistical significance was set at a $p$ value of 0.05 , Bonferroni corrected for multiple comparisons over 4 corticospinal tracts. Consistency between the 2 methods was evaluated with 2-way mixed-model intraclass correlation coefficient (ICC) $)^{7}$ and Pearson correlation coefficients (figure 3). See e-Methods on the Neurology ${ }^{\circledR}$ Web site at www.neurology.org for additional methodologic details.

Standard protocol approvals, registrations, and patient consents. Written consent was obtained from all participants. The study was approved by the Joint Ethics Committee of the
Institute of Neurology (UCL) and National Hospital for Neurology and Neurosurgery (UCLH NHS Trust), London.

RESULTS Fifty-one patients (53.9 \pm 12.7 years) and 23 age-matched healthy volunteers $(50.6 \pm 14.7$ years) were recruited. Characteristics of the patient group are provided in table e-1. Patients had a range of upper limb impairments (ARAT: 19-57; NHPT: 0-104.5; Motricity Index: 42-100; grip strength: 18.2-111.7). The first principal component of these 4 scores explained $71.3 \%$ of the total behavioral variance. Overlap values correlated with impairment for all 4 cortical motor regions with both automated (M1: $r=0.56, p<0.001$, figure 2; PMd: $r=0.57$, $p<0.001$; PMv: $r=0.45, p=0.001$; SMA: $r=$ $0.42, p=0.002)$ and manual methods (M1: $r=0.46$, $p=0.001$, figure 2; PMd: $r=0.43, p=0.002$; PMv: $r=0.32, p=0.022$; SMA: $r=0.34, p=0.010$ ). Fisher $r-z$ transformations showed no significant differences between correlation coefficients for any of the 4 corticospinal tract pairs using each method (table e-2). Further, in comparing automated and manual methods, Pearson correlation coefficients and ICCs (range $=0.71-0.80$ ) from all cortical motor regions indicate good to excellent consistencies between the 2 methods (figure 3, table e-3). ICC values above 0.75 demonstrate an excellent level of consistency. ${ }^{7}$ Controlling for age and time since stroke had no significant effects in correlations with impairment.

Figure 1 Overview of infarct definition and overlap techniques

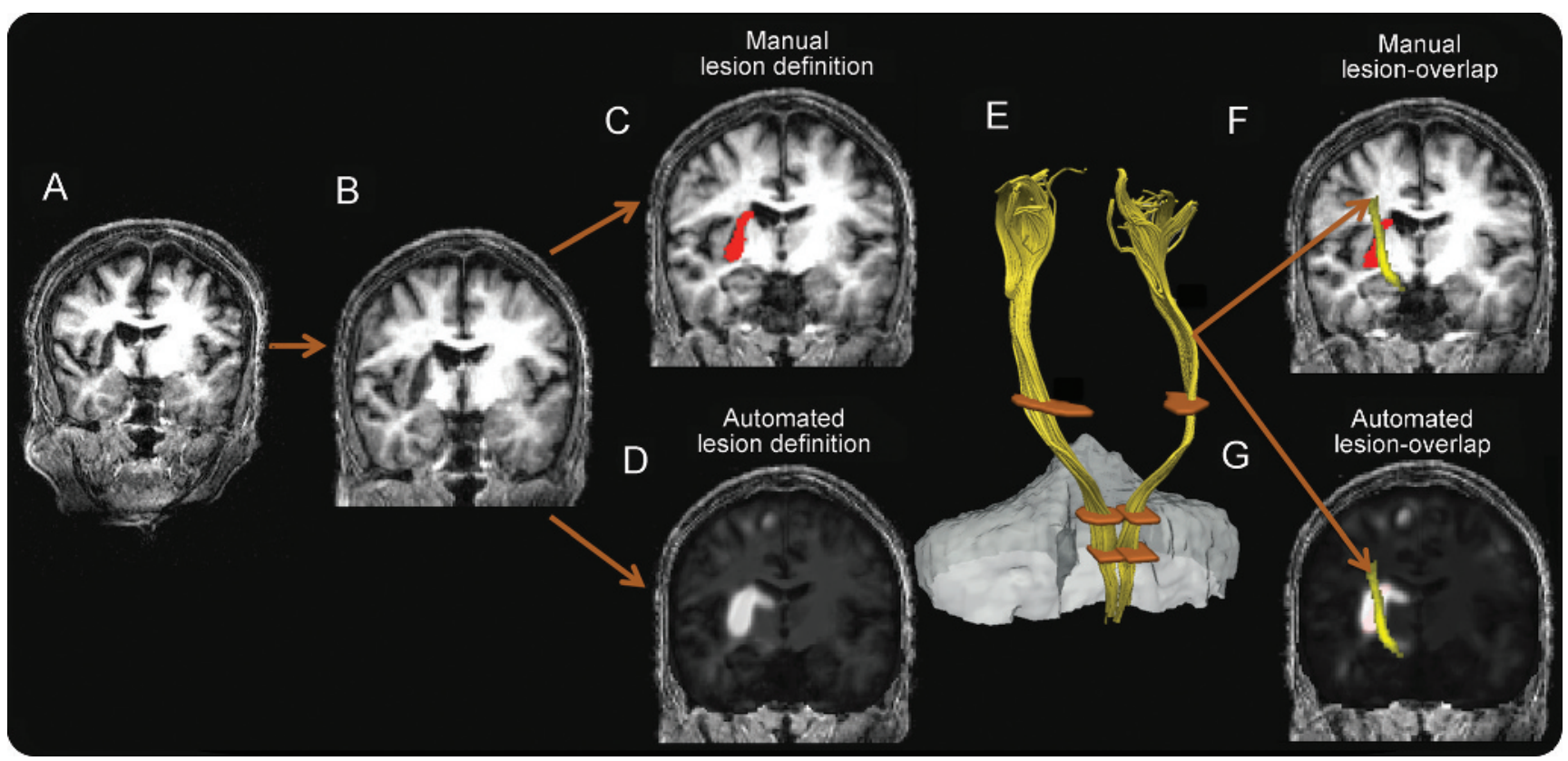

First, T1-weighted structural images (A) from patients were spatially normalized (B). Then, infarcts were defined manually (C, in red) or automatically (D, in light gray). Normal template corticospinal tracts were reconstructed through the regions of interest (posterior limb of internal capsule, and upper and lower pons), and with an exclusion mask (E). Template corticospinal tracts were then overlapped with the manually (F) and automatically (G) defined infarcts. 
Figure 2 Automated and manual lesion-overlaps with template corticospinal tract from primary motor cortex ( $\mathrm{n}=51$ )

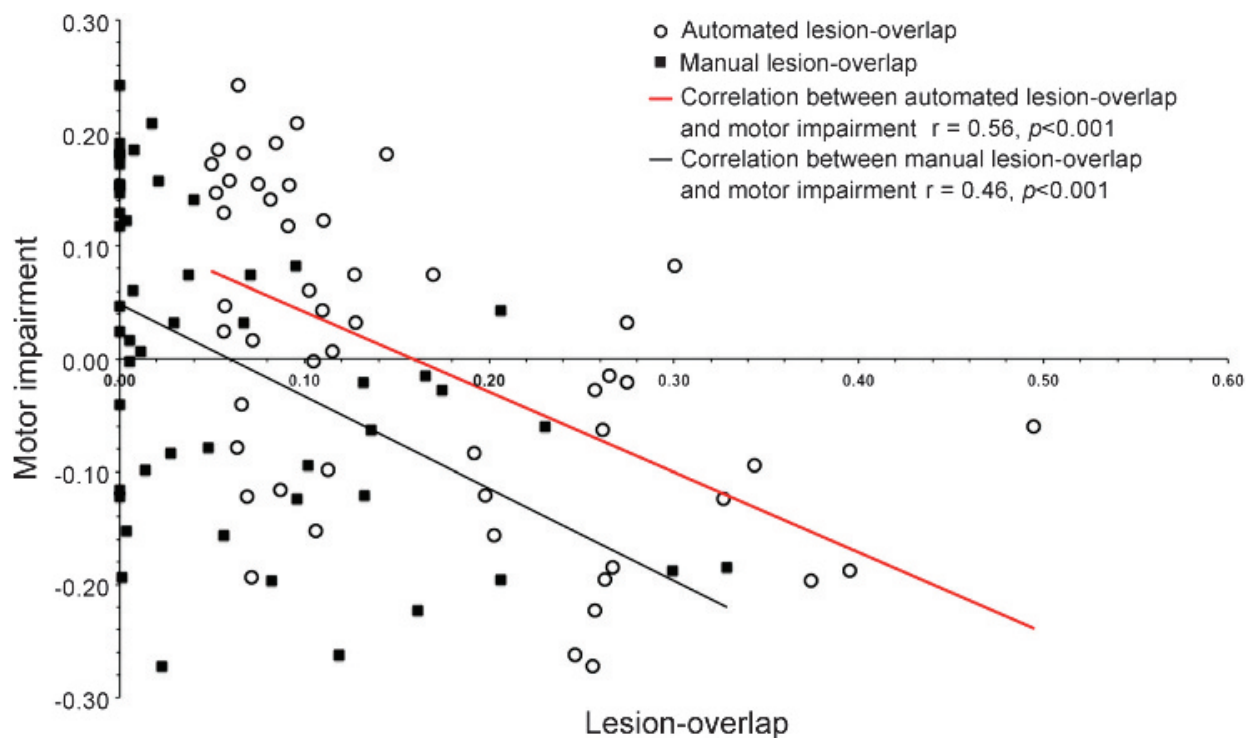

Overlap of corticospinal tract from the primary motor cortex (M1) and infarct determined from manual (black squares) and automated (open circles) methods plotted against motor impairment (automated: $r=0.56, p<0.001$; manual: $r=0.46, p<$ 0.001). Similar correlations with motor impairment between the 2 overlap methods are supported by a Fisher $r-z$ transformation (M1: $p=0.509$ ). Similar results were obtained using weighted tracts defined th the group level without binarization; see e-Results for more details.

DISCUSSION We have demonstrated that manual and automated methods of infarct identification produce similar results when used to assess the degree of overlap with the corticospinal tract in chronic stroke patients. Overlap with corticospinal tracts has previously been examined using only manually defined lesion volumes, limiting the generalizability of the approach. ${ }^{1,2}$ There is no gold standard for defining the degree of corticospinal tract damage after stroke, but here we have used correlation with upper limb impairment as a way of assessing the clinical validity of our measures.

In the majority of patients, the automated method yielded larger tract-infarct overlap volumes. This may

Figure 3 Correlation between automated and manual lesion-overlaps with corticospinal tract from primary motor cortex $(n=51)$

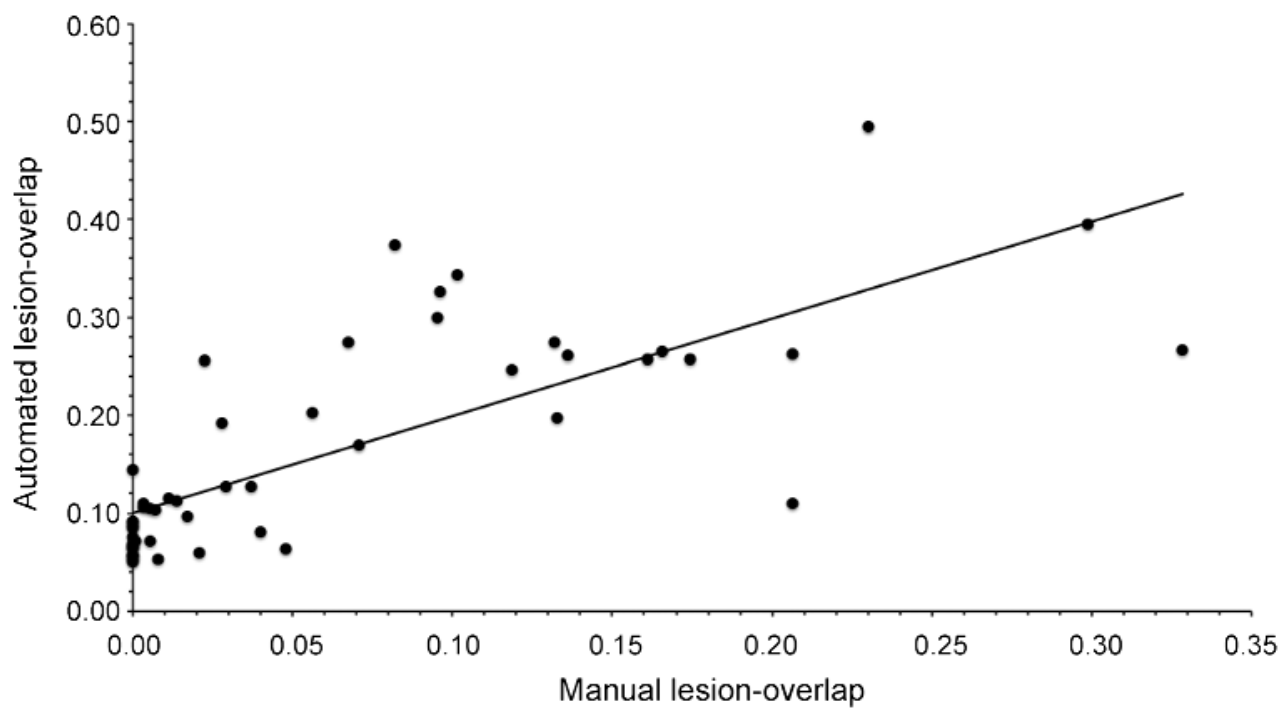

Pearson correlation coefficient of $0.73(p<0.001)$ and interclass correlations of $0.71(p<0.0125)$ indicate good to excellent consistency between the 2 overlap methods. 
be attributable to the sensitivity of the fully automated procedure in detecting additional pertinent voxel abnormalities in T1-weighted images, including small-vessel disease and ventricular dilations. ${ }^{6} \mathrm{~A}$ direct meaningful comparison between the 2 methods is not possible, however, as they are dissimilar in their measurements. ${ }^{6}$ We did not perform tractography in the patients as a result of insufficient intact fibers within and around the infarcted area, thus healthy control templates were used instead.

Further, we have confirmed that the degree of corticospinal tract injury determined with either method was consistent and correlated with motor impairment in agreement with previous research, particularly for tracts originating in $\mathrm{M} 1$ and PMd. ${ }^{1,2,8}$ Independent injury to the tracts descending from PMv and SMA, however, seems less relevant for predicting impairment in comparison to injury to those from PMd and M1.

Our results show that corticospinal tract damage to M1 or PMd accounts for only approximately 30\% of the interpatient variability in chronic-stage motor impairment, which is partly attributable to our sample of chronic stroke patients in whom a degree of reorganization is likely to have occurred since the original injury (table e-2). The relatively low correspondence between upper limb function and corticospinal tractspecific integrity may also be related to damage to important non-corticospinal tract cortical regions ${ }^{9}$ or even chronic changes in muscle bulk or tone that may alter upper limb motor performance. Further, correlation between corticospinal tract damage and upper limb impairment is likely to be stronger when assessed early after stroke, ${ }^{10}$ suggesting that early evaluation of corticospinal tract integrity with long-term follow-up may be pertinent in inferring motor outcome. Our results demonstrate equivalence between automated and manual lesion identification approaches, opening the way for large-scale prospective longitudinal studies of the utility of unbiased assessment of corticospinal tract integrity early after stroke in predicting late motor outcome after stroke.

\section{AUTHOR CONTRIBUTIONS}

Nancy Kou drafted the manuscript, contributed to data and statistical analyses, and made intellectual contribution including design of the study. Chang-hyun Park revised the manuscript, contributed to data and statistical analyses, and made intellectual contribution including design of the study. Mohamed L. Seghier revised the manuscript and contributed to data interpretation. Alexander P. Leff revised the manuscript and contributed to data interpretation. Nick S. Ward revised the manuscript, contributed to data interpretation, and made intellectual contribution including design of the study.

\section{STUDY FUNDING}

Supported by The Wellcome Trust (N.W., C.H.P.) and European Commission under seventh Framework Program-HEALTH-Collaborative Project Plasticise (contract no. 223524)—www.plasticise.eu (N.W.). The study is not industry-sponsored.

\section{DISCLOSURE}

The authors report no disclosures relevant to the manuscript. Go to Neurology.org for full disclosures.

Received November 12, 2012. Accepted in final form March 1, 2013.

\section{REFERENCES}

1. Zhu LL, Lindenberg R, Alexander MP, Schlaug G. Lesion load of the corticospinal tract predicts motor impairment in chronic stroke. Stroke 2010;41:910-915.

2. Riley JD, Le V, Der-Yeghiaian L, et al. Anatomy of stroke injury predicts gains from therapy. Stroke 2011;42:421-426.

3. Newton JM, Ward NS, Parker GJM, et al. Non-invasive mapping of corticofugal fibres from multiple motor areas: relevance to stroke recovery. Brain 2006;129:1844-1858.

4. Ashton EA, Takahashi C, Berg MJ, Goodman A, Totterman S, Ekholm S. Accuracy and reproducibility of manual and semiautomated quantification of MS lesions by MRI. J Magn Reson Imaging 2003;17:300-308.

5. Behrens TE, Woolrich MW, Jenkinson M, et al. Characterization and propagation of uncertainty in diffusion-weighted MR imaging. Magn Reson Med 2003;50:1077-1088.

6. Seghier ML, Ramlackhansingh A, Crinion J, Leff AP, Price CJ. Lesion identification using unified segmentationnormalisation models and fuzzy clustering. Neuroimage 2008; 41:1253-1266.

7. Shrout PE, Fleiss JL. Intraclass correlations: uses in assessing rater reliability. Psychol Bull 1979;86:420-428.

8. Schulz R, Park CH, Boudrias MH, Gerloff C, Hummel FC, Ward NS. Assessing the integrity of corticospinal pathways from primary and secondary cortical motor areas after stroke. Stroke 2012;43:2248-2251.

9. Gauthier LV, Taub E, Mark VW, Barghi A, Uswatte G. Atrophy of spared gray matter tissue predicts poorer motor recovery and rehabilitation response in chronic stroke. Stroke 2012;43:453-457.

10. Swayne OB, Rothwell JC, Ward NS, Greenwood RJ. Stages of motor output reorganization after hemispheric stroke suggested by longitudinal studies of cortical physiology. Cereb Cortex 2008;18:1909-1922. 


\section{Neurology}

Can fully automated detection of corticospinal tract damage be used in stroke patients?

Nancy Kou, Chang-hyun Park, Mohamed L. Seghier, et al.

Neurology 2013;80;2242-2245 Published Online before print May 8, 2013

DOI 10.1212/WNL.0b013e318296e977

This information is current as of May 8, 2013

\begin{tabular}{|c|c|}
\hline $\begin{array}{l}\text { Updated Information \& } \\
\text { Services }\end{array}$ & $\begin{array}{l}\text { including high resolution figures, can be found at: } \\
\text { http://n.neurology.org/content/80/24/2242.full }\end{array}$ \\
\hline Supplementary Material & $\begin{array}{l}\text { Supplementary material can be found at: } \\
\text { http://n.neurology.org/content/suppl/2013/05/08/WNL.0b013e318296e } \\
\text { 977.DC1 }\end{array}$ \\
\hline References & $\begin{array}{l}\text { This article cites } 10 \text { articles, } 4 \text { of which you can access for free at: } \\
\text { http://n.neurology.org/content/80/24/2242.full\#ref-list-1 }\end{array}$ \\
\hline Subspecialty Collections & $\begin{array}{l}\text { This article, along with others on similar topics, appears in the } \\
\text { following collection(s): } \\
\text { All Rehabilitation } \\
\text { http://n.neurology.org/cgi/collection/all_rehabilitation } \\
\text { Infarction } \\
\text { http://n.neurology.org/cgi/collection/infarction } \\
\text { MRI } \\
\text { http://n.neurology.org/cgi/collection/mri }\end{array}$ \\
\hline Permissions \& Licensing & $\begin{array}{l}\text { Information about reproducing this article in parts (figures,tables) or in } \\
\text { its entirety can be found online at: } \\
\text { http://www.neurology.org/about/about_the_journal\#permissions }\end{array}$ \\
\hline Reprints & $\begin{array}{l}\text { Information about ordering reprints can be found online: } \\
\text { http://n.neurology.org/subscribers/advertise }\end{array}$ \\
\hline
\end{tabular}

Neurology ${ }^{\circledR}$ is the official journal of the American Academy of Neurology. Published continuously since 1951, it is now a weekly with 48 issues per year. Copyright (C 2013 American Academy of Neurology. All rights reserved. Print ISSN: 0028-3878. Online ISSN: 1526-632X.

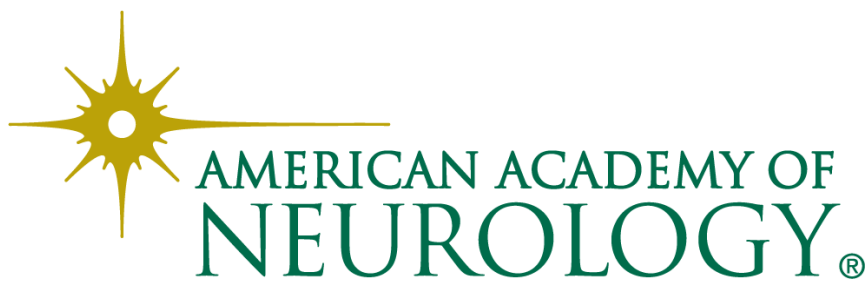

